\title{
Comparative study of classic friction among different archwire ligation systems
}

Gilberto Vilanova Queiroz', José Rino Neto², João Batista De Paiva³ ${ }^{3}$ Jesualdo Luís Rossi ${ }^{4}$, Rafael Yagüe Ballester ${ }^{5}$

Objective: To describe and compare three alternative methods for controlling classical friction: Self-ligating brackets (SLB), special brackets (SB) and special elastomeric ligatures (SEB).

Methods: The study compared Damon MX, Smart Clip, In-Ovation and Easy Clip self-ligating bracket systems, the special Synergy brackets and Morelli's twin bracket with special 8-shaped elastomeric ligatures. New and used Morelli brackets with new and used elastomeric ligatures were used as control. All brackets had 0.022 x 0.028-in slots. 0.014-in nickel-titanium and stainless steel $0.019 \times 0.025$-in wires were tied to first premolar steel brackets using each archwire ligation method and pulled by an Instron machine at a speed of $0.5 \mathrm{~mm} / \mathrm{minute}$. Prior to the mechanical tests the absence of binding in the device was ruled out. Statistical analysis consisted of the KruskalWallis test and multiple non-parametric analyses at a $1 \%$ significance level.

Results: When a 0.014-in archwire was employed, all ligation methods exhibited classical friction forces close to zero, except Morelli brackets with new and old elastomeric ligatures, which displayed 64 and 44 centiNewtons, respectively. When a $0.019 \times 0.025$-in archwire was employed, all ligation methods exhibited values close to zero, except the In-Ovation brackets, which yielded $45 \mathrm{cN}$, and the Morelli brackets with new and old elastomeric ligatures, which displayed 82 and 49 centiNewtons, respectively.

Conclusions: Damon MX, Easy Clip, Smart Clip, Synergy bracket systems and 8-shaped ligatures proved to be equally effective alternatives for controlling classical friction using 0.014-in nickel-titanium archwires and $0.019 \mathrm{x}$ 0.025-in steel archwires, while the In-Ovation was efficient with 0.014-in archwires but with $0.019 \times 0.025$-in archwires it exhibited friction that was similar to conventional brackets with used elastomeric ligatures.

Keywords: Corrective Orthodontics. Orthodontic brackets. Friction.

${ }^{1}$ Professor of Specialization Course in Orthodontics, ABENO/SP.

${ }^{2}$ Associate Professor of Orthodontics, Department of Orthodontics and Pediatric Dentistry, FO-USP.

${ }^{3}$ Associate Professor of Orthodontics, Department of Orthodontics and Pediatric Dentistry, FO-USP.

${ }^{4} \mathrm{PhD}$, professor at IPEN.

${ }^{5}$ Full Professor of Dental Materials, FOUSP.
How to cite this article: Queiroz GV, Rino Neto J, De Paiva JB, Rossi JL, Ballester RY. Comparative study of classic friction among different archwire ligation systems. Dental Press J Orthod. 2012 May-June;17(3):64-70. Submitted: January 05, 2009 - Revised and accepted: October 20, de 2010
» The authors report no commercial, proprietary or financial interest in the products
or companies described in this article.

» Patients displayed in this article previously approved the use of their facial and intraoral photographs.

Contact address: Gilberto Vilanova Queiroz

Av. Major Alfredo Camargo da Fonseca, 251 - Centro, Indaiatuba/SP - Brazil

Zip code: 13.334-060 - E-mail: gilbertovilanova@terra.com.br 


\section{INTRODUCTION}

In the early days of Orthodontics, tooth movements were carried out by means of removable appliances combined with springs and elastics. A major shortcoming of these mechanical devices were undesirable tooth inclinations. Accurate tooth movement control only became possible with the advent of the Edgewise appliance, a historic breakthrough in orthodontics that provided controlled tooth movements by means of orthodontic archwires inserted in bracket slots.

Sliding mechanics between archwire and bracket slot incorporated friction forces into orthodontic practice. Kusy and Whitley ${ }^{12}$ classified friction into three major types:

1. Classical friction: Caused by conventional ligation as it compresses the archwire against the bottom of the bracket slot.

2. Binding: Friction produced through deformation of the archwire as it compresses the bracket slot walls.

3. Notching: Friction produced by excessive deformation of the archwire, causing the archwire and bracket to interlock, thereby hindering tooth movement.

Binding is inherent in the dental alignment stage since at this stage the slots are in different planes and thus cause archwire deformation, which in turn produces the forces responsible for tooth movement. On the other hand, classical friction is optional as it is present only if conventional ligatures are used to secure the archwires in the slots.

It is important to control classical friction in order to identify the real magnitude of orthodontic forces delivered to the periodontium, increasing reproducibility in sliding mechanics. ${ }^{12}$ The mechanisms normally associated with classical friction control are self-ligating brackets, which eliminate the need for elastomeric or steel ligatures to hold the orthodontic archwire in the slot.

Designed to be used with conventional brackets, special elastomeric ligatures are another resource geared at reducing classical friction. Their innovative design retains the orthodontic archwire without pressing it against the bottom of the slot. Upon insertion, the central body rests on the buccal surface of the bracket while the extensions are positioned under the tie-wings (Fig 1). In this situation the central portion acts as a cover, closing the slot but leaving the orthodontic archwire loose in the slot. The product is marketed by two companies, i.e., Leone, under the brand name Slide and Tecnident's 8-shaped ligatures (Fig 2).

Classical friction can also be controlled with special brackets that allow one to seat the orthodontic archwire actively or passively according to the insertion site of conventional elastomeric ligatures. An example of special brackets is the Synergy orthodontic appliance, manufactured by Rocky Mountain Orthodontics. Synergy features six tie-wings instead of the four present in twin brackets. For a passive system, one should place a conventional elastomeric ligature under the central tie-wings only, so that the ligature remains supported on the lateral extensions of the central tie-wings (Fig 3A). When an active system is desired, a conventional elastomeric ligature is placed under the lateral tie-wings. In this configuration the ligature is made to rest on the orthodontic archwire, compressing it against the bottom of the slot (Fig 3B).

Since different appliances are available for controlling classical friction, the aim of this study was to
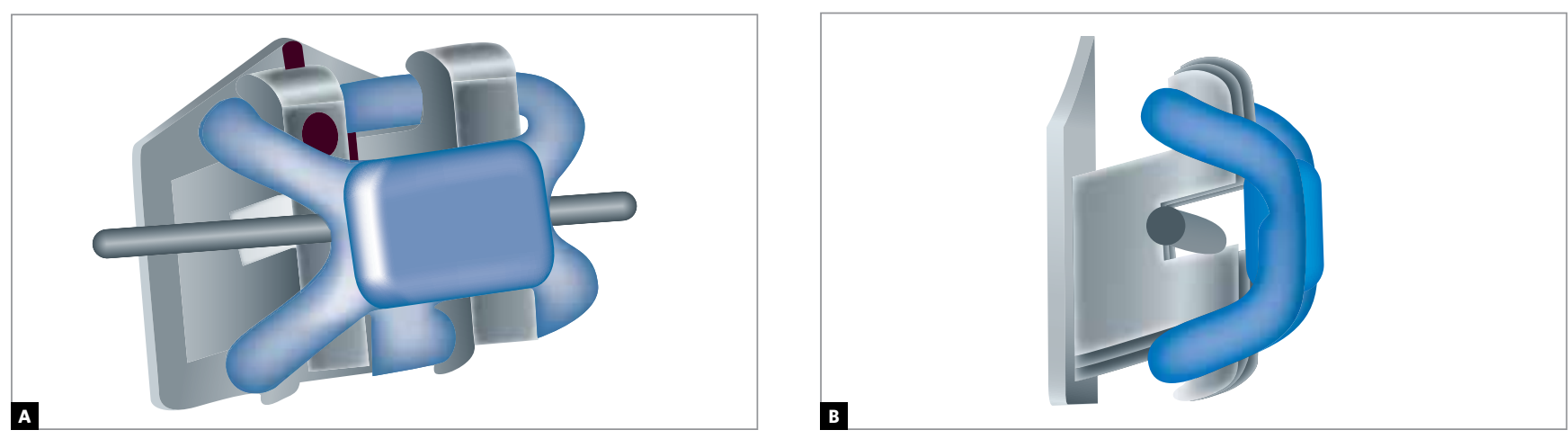

Figure 1 - Slide ligatures: A) Frontal view, and B) side view. (Source: Catalog Leone Ortodonzia) 

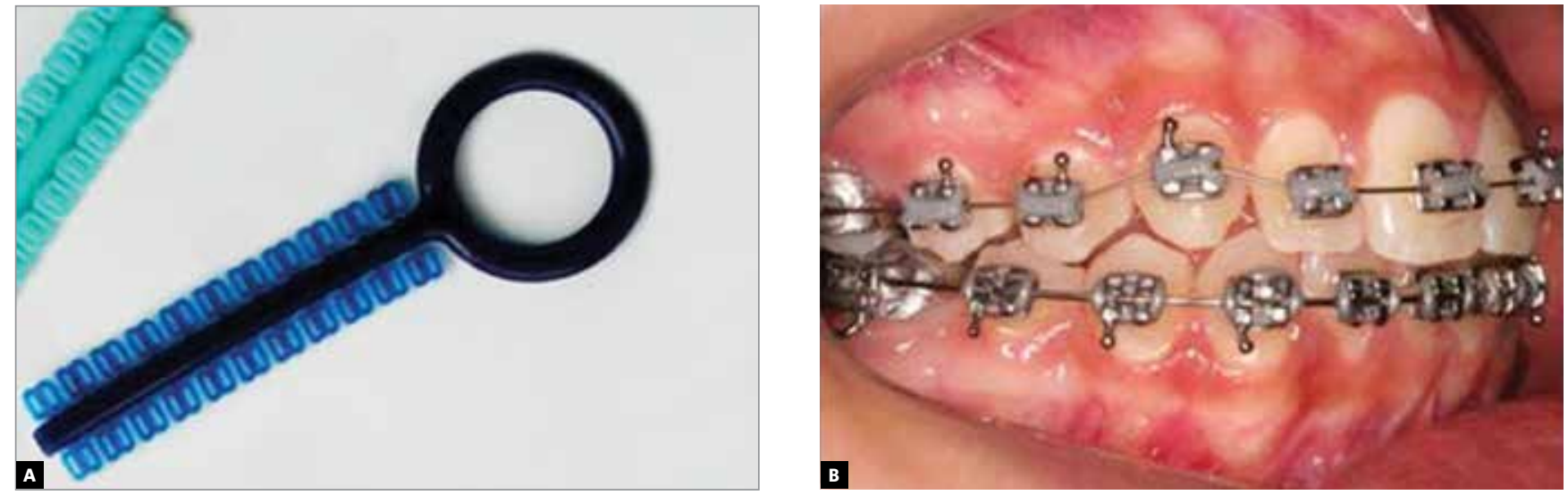

Figure 2 - A) Special 8-shaped elastomeric ligature; B) 8-shaped ligature in the upper arch.
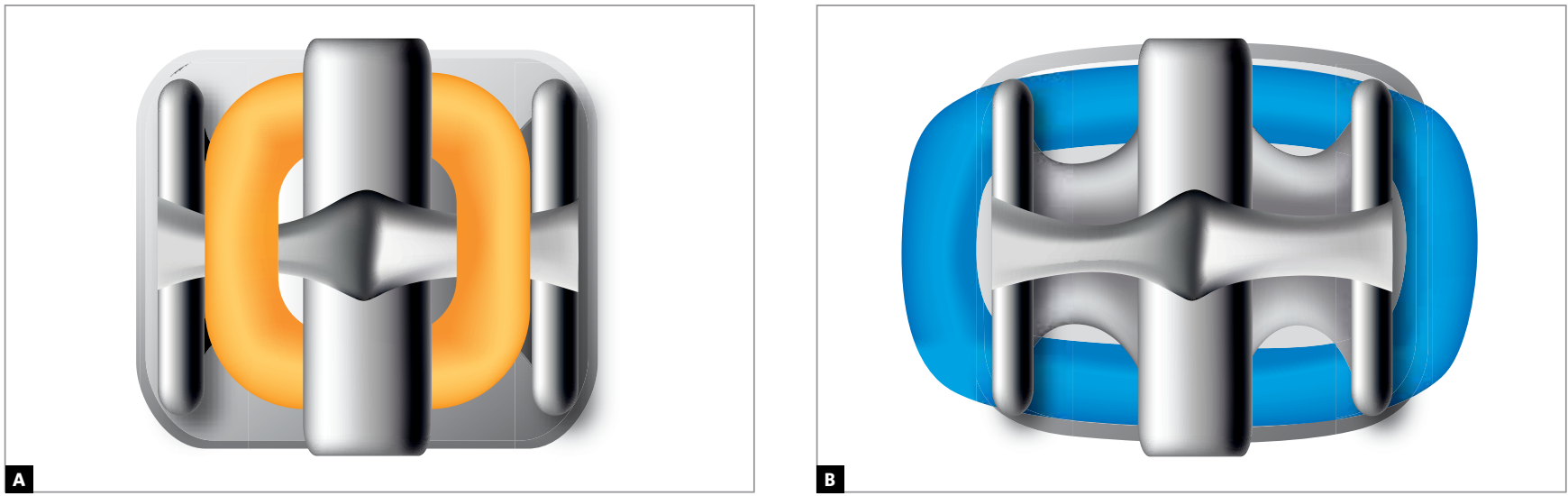

Figure 3 - Synergy bracket: A) Passive system, B) Active System. (Source: Catalog Rocky Mountain Orthodontics)

compare the effectiveness of self-ligating brackets, the special Synergy bracket and 8-shaped ligatures in reducing classical friction.

\section{MATERIAL AND METHODS}

The following archwire ligation methods were compared:

» Damon MX (Ormco), Easy Clip (Aditek), Smart Clip (3M/Unitek) and In-Ovation (GAC) selfligating brackets.

» Special Synergy brackets (Rocky Mountain) with new elastomeric ligatures tied to the center tie-wings.

» Conventional twin bracket (Morelli) with 8-shaped ligature (Tecnident).

» Conventional twin bracket (Morelli) with new elastomeric ligature.

» Conventional twin bracket (Morelli) with used elastomeric ligature.

The elastomeric ligatures employed in this study were manufactured by Morelli. They were gray in color and with an internal diameter of $1.2 \mathrm{~mm}$. To simulate the relaxed state produced by the stretching of the elastomeric ligature, ligatures designated as "used" were placed on a cylinder with $3 \mathrm{~mm}$ diameter, where they remained for 36 hours before being used to tie the wires to the brackets.

First premolar steel brackets with $0.022 \times 0.028$-in slots were employed. All brackets were bonded to a device with two $0.022 \times 0.028$-in guiding slots at the ends of the area designed to receive the brackets (Fig 4). Cyanoacrylate was used to perform the direct bonding 
of the brackets with the aid of a standard 0.022" thickness ruler simultaneously in the guiding slots and bracket slots (Fig 5).

Tests were carried out on segments of 0.014-in Contour NiTi and $0.019 \times 0.025$-in steel wire, both manufactured by Aditek. All wires were 12-in long. In each test the wire was stabilized inside the slot by means of covers or clips on the self-ligating brackets, 8-shaped ligatures on the Morelli brackets, new elastomeric ligatures on the center tie-wings of Synergy brackets and new and used elastomeric ligatures on the control twin brackets.

Classical friction forces were recorded during wire traction until total displacement reached $2 \mathrm{~mm}$. A model 5565 Instron universal mechanical testing machine was used with a load cell of 500 Newtons and bridging speed of $0.05 \mathrm{~mm} /$ minute. Parallelism between the device and the Instron machine vise was obtained by inserting the tip of a 0.022 " standard ruler into the guiding slots while the opposite end contacted the right wall of the vise, which remained stationary. Closing and opening the vise was made possible by lateral displacement of the left movable wall (Fig 6).

The rectangular steel wire was not attached directly to the Instron machine vise in order to prevent any potential friction from being produced by wire torsion (third order friction). The rectangular wire was bent at its end and inserted - in juxtaposition - into the steel tube, which was attached to the vise. Thus, the rectangular wire remained in the bracket slot and loose inside the steel tube, which was pulled through the upper displacement of the Instron machine's crossbar (Figs 7A and B).

Each test was repeated eight times with the wires and elastomeric ligatures being replaced prior to each test. The tests were performed in a dry medium at a temperature between 24 and 26 degrees Celsius.

Before each test, the wire that had been inserted into the slot and attached to the Instron machine was pulled unligated to check whether sliding took place without resistance, which confirmed the absence of binding in the tests.

Means, standard deviations, minimum and maximum friction force values were calculated for each group tested. Comparisons between the archwire ligation systems were conducted using the Kruskal-Wallis test as well as multiple non-parametric analyses with a $1 \%$ significance level.

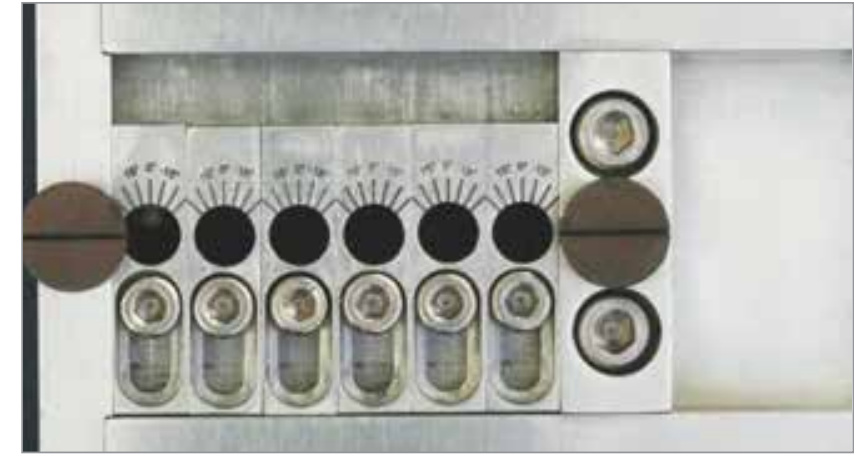

Figure 4 - Device with guiding slots at both ends.

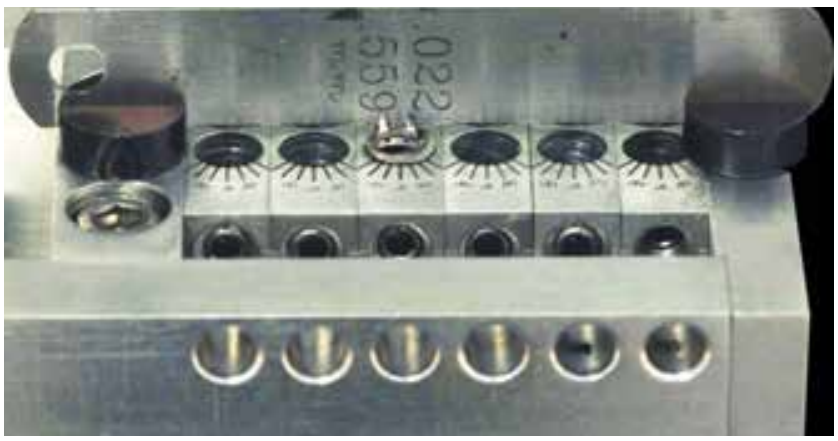

Figure 5 - Placement of the bracket on the device.

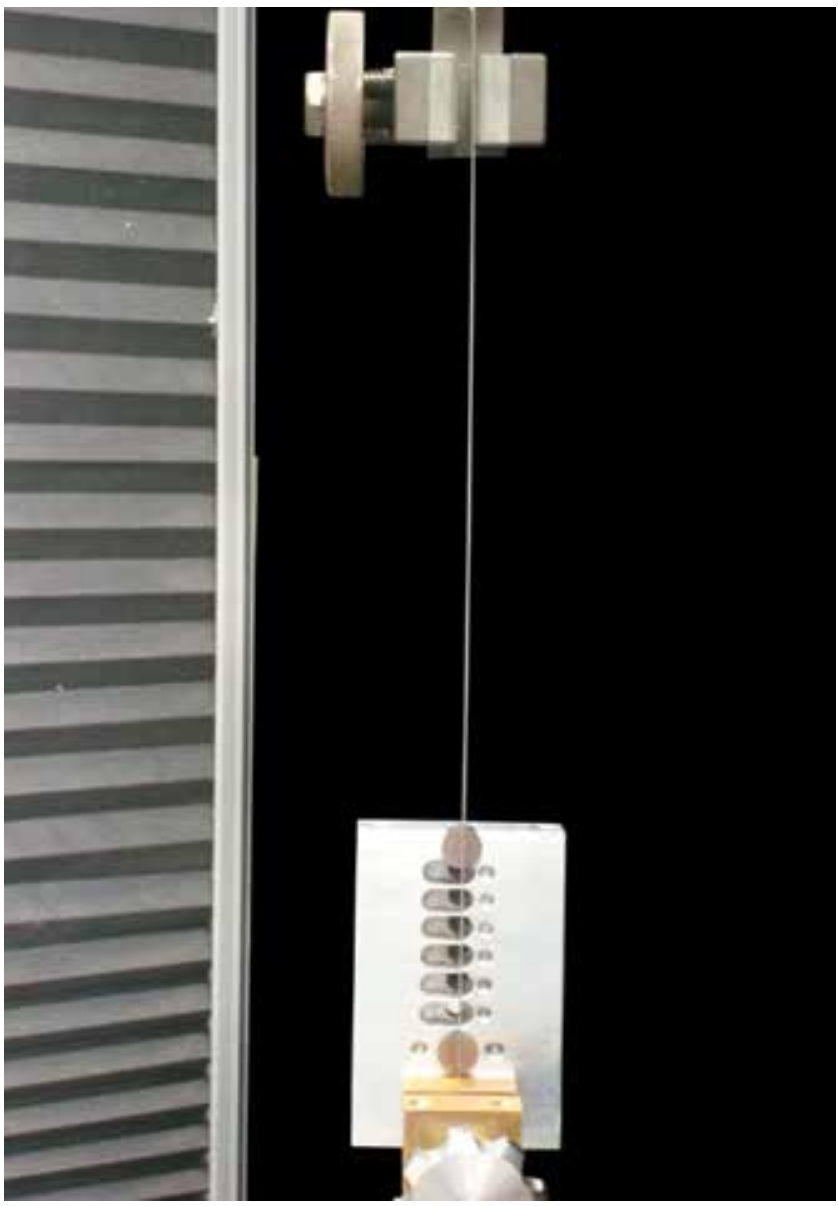

Figure 6 - Device positioning and 0.014-in contour NiTi wire on the Instron machine. 

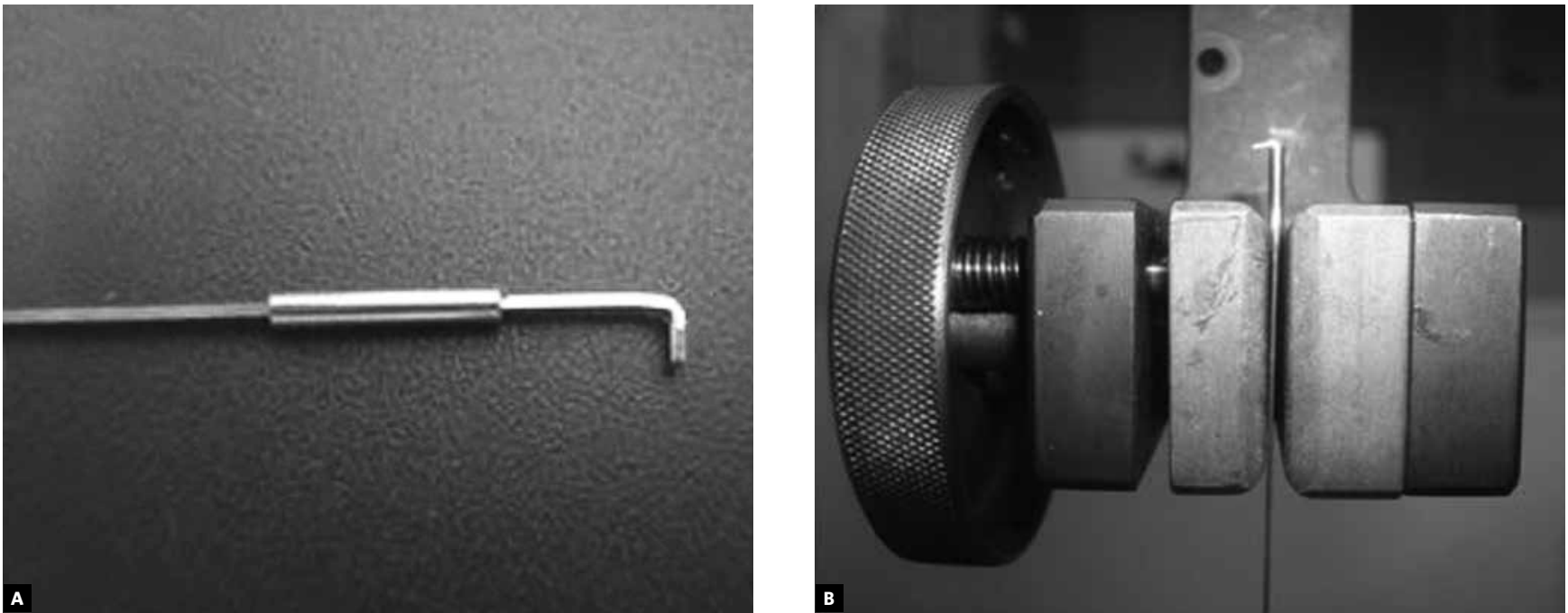

Figure 7 - A) Set comprised of $0.019 \times 0.025$-in rectangular wire and steel tube; B) set positioned on the vise

\section{RESULTS}

The descriptive analysis of classical friction in 0.014in Contour NiTi wires is shown in Table 1. The archwire ligation methods were distributed across three groups (A, B, C) according to statistically significant differences. Group A: Damon MX, Easy Clip, In-Ovation, SmartClip and Synergy brackets, and 8-shaped ligatures with mean values close to zero; Group B: Conventional Morelli brackets with used ligatures and means of $44 \mathrm{cN}$; and Group C: Conventional Morelli brackets with new ligatures and means of $66 \mathrm{cN}$.

\section{DISCUSSION}

The purpose of this study was to compare the magnitude of classical friction among different orthodontic archwire ligation methods, including two Brazilian products recently launched on the market: Easy Clip self-ligating brackets and 8-shaped ligature. 0.014-in Contour NiTi wire and $0.019 \times 0.025$-in steel wire were tested with the aim of assessing the magnitude of classical friction both in the phase of leveling and in the anterior retraction stage.

When using 0.014-in NiTi wires, the classical friction force produced by new elastomeric ligatures displayed a mean of $64 \mathrm{cN}$, an intermediate value between those found in other studies, which ranged between 31 and $119 \mathrm{cN}^{1,3,7,20}$ The 8-shaped ligature and Damon MX, Smart Clip, In-Ovation, Easy Clip and Synergy brackets exhibited friction levels approaching zero, and the differences exhibited by the new elastomeric ligatures were statistically significant, yielding results that corroborate those found in the literature. . $^{1,4,6,7}$
Table 1 - Descriptive analysis and comparisons between classical friction forces (cN) of 0.014-in Contour NiTi wire.

\begin{tabular}{llccccc} 
Groups & Brackets & Mean & s.d. & Min. & Max. & \# sig.* \\
\hline A & D, EC, IO, SC, S, A8 & 0,6 & 0,4 & 0 & 1,3 & $B, C$ \\
B & Used ligature & 44 & 17 & 18 & 68 & $A, C$ \\
C & New ligature & 66 & 10 & 49 & 79 & A,B \\
\hline
\end{tabular}

D: Damon MX; EC: Easy Clip; IO: In-Ovation; SC: SmartClip; S: Synergy; A8: 8-shaped ligature. ${ }^{\star} p<0.01$

Table 2 - Descriptive analysis and comparisons between classical friction forces $(\mathrm{cN})$ in $0.019 \times 0.025$-in steel wires.

\begin{tabular}{llccrrc}
\hline Groups & Brackets & Mean & s.d. & Min. & Max. & \# sig. \\
\hline D & D, EC, SC, S, A8 & 0,7 & 0,5 & 0,1 & 1,5 & E,F \\
E & IO & 45 & 11 & 28 & 59 & D,F \\
E & Used ligature & 49 & 11 & 33 & 65 & D,F \\
F & New ligature & 82 & 15 & 52 & 97 & D,E \\
\hline
\end{tabular}

D: Damon MX; EC: Easy Clip; IO: In-Ovation; SC: SmartClip; S: Synergy; A8: 8-shaped ligature. ${ }^{*} p<0.01$

In general, tests with round wires tied with elastomeric ligatures displayed a high magnitude of classical friction. Most in vitro studies, however, employ new elastomeric ligatures, which is a limitation since in clinical conditions elastomeric ligatures subjected to stretching are permanently deformed, reducing the contact force between orthodontic wire and bracket. ${ }^{16,17}$ In this study, a statistically significant difference found in the magnitude of classical friction between the new ligatures $(64 \mathrm{cN})$ and the used ligatures subjected to stretching for 36 hours $(44 \mathrm{cN})$ confirmed the relaxing influence of elastomeric ligatures on the reduction of classical friction. 
When using $0.019 \times 0.025$-in steel wire, the brackets with new (unused) ligatures exhibited a mean friction of $82 \mathrm{cN}$, significantly higher than the value exhibited by the used elastomeric ligature, which reached $49 \mathrm{cN}$, an outcome that was similar to that recorded for the active In-Ovation brackets, whose mean was $45 \mathrm{cN}$. The high magnitude of classical friction exhibited by active self-ligating brackets with rectangular $0.019 \times 0.025$-in wire reinforces the advantage of using space closing loops, which produces a friction-free mechanics.

Moreover, regarding the rectangular $0.019 \times 0.025$ in wire, Damon , Easy Clip, Smart Clip, Synergy and 8-shaped ligatures showed levels of friction close to zero, with results that were similar to those found by Hain, ${ }^{9}$ Griffths $^{8}$ and Gandini, ${ }^{7}$ however other investigations found significant friction forces in passive self-ligating brackets with large cross-section archwires. ${ }^{2,5,18,19}$ Such differences are probably related to (a) the number of brackets used in the clinical simulation device and (b) to a misalignment between slot and testing machine. These factors reduce the slack between wire and bracket slot, predisposing to the emergence of binding.

The angle at which the slack between wire and slot disappears, known as critical contact angle, constitutes a milestone in the evaluation of classical friction because it is at this point that the contact force between archwire and bracket slot occurs, thereby producing binding, which is incorporated into the total friction and prevents classical friction from being assessed separately. ${ }^{19}$ For this reason, it is important that researches be conducted on the friction produced by the various ligation methods be ensured of the absence of binding during mechanical tests.

The second order critical angle (mesiodistal direction), between a $0.019 \times 0.025$-in rectangular wire and a $0.022 \times 0.028$-in slot bracket with a width of $3.5 \mathrm{~mm}$ is of approximately $1.5^{0} .^{11}$ The greater the bracket width, the lower the second order critical angle, which increases the likelihood of binding ${ }^{13}$ (Fig 8). In classical friction tests where the archwire is made to slide along several brackets, the second order critical angle is even smaller as the width in question corresponds to the distance between the brackets located at the ends. Therefore, even a minor misalignment between wire and slots will produce a contact between wire and bracket slots, as well as binding, which increases the total friction and hampers the measurement of classical friction separately. ${ }^{19}$ Thus, in order to reduce the likelihood of bias caused by binding it is convenient to use only one bracket in tests that assess the magnitude of classical friction.

The method used to insert the wire into the Instron machine is yet another factor that can reduce the slack between the rectangular wire and the slot, thus producing binding. Wire insertion is usually accomplished by means of a latch or a vise. This maneuver, however, can twist the wire and cause third order binding (buccolingual direction). ${ }^{13}$ The third order critical angle between a rectangular $0.019 \times 0.025$-in wire and a $0.022 \times 0.028$ in bracket slot is about 87 degrees, a value that reflects the limit of wire rotation upon insertion of such wire in the testing machine ${ }^{13}$ However, torque also affects the second order critical angle. Rectangular wire torsion increases the effective height of the rectangular wire, decreasing the slack in the slot and further reducing even more the second order critical angle, which raises the likelihood of binding. ${ }^{11,13}$

In this research, due to technical limitations which made it difficult to achieve absolute alignment between the slot and the rectangular wire attached directly to the vise, it was decided to install between the vise walls a steel tube with the rectangular wire loose in its interior. In this way, the method used to attach the wire to the Instron machine did not interfere with the relationship between archwire and slot, thereby averting rectangular archwire torsion (Fig 7).

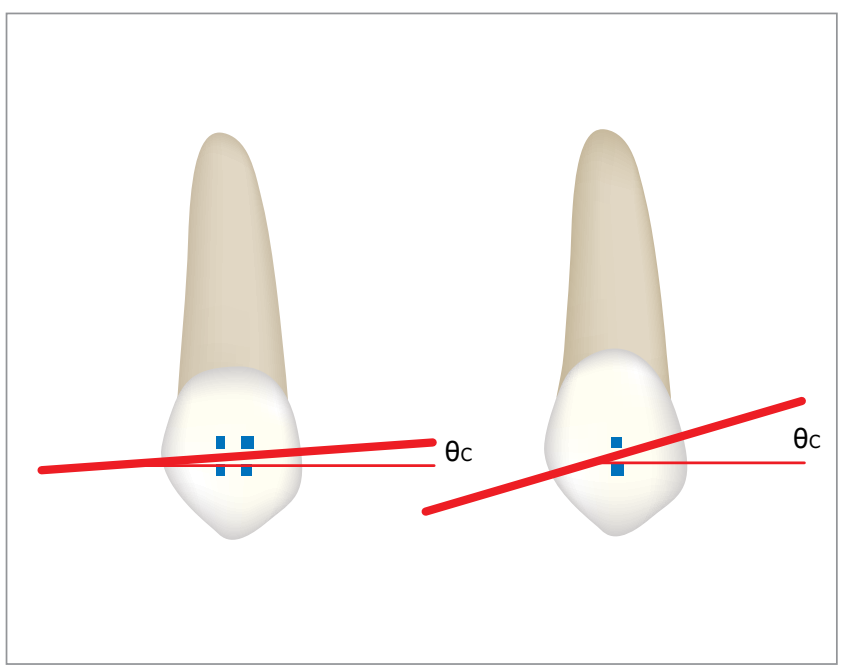

Figure 8 - Influence of bracket on second order critical angle: the greater the bracket width of the bracket, the smaller the second order critical angle $(\theta c)$. 
In addition to adopting a methodology to avoid the bias produced by binding it is necessary to verify the effectiveness of such method prior to performing classical friction assessment tests. In this study, such confirmation was achieved by pulling the archwire inside the slot without the use of any ligation system. In this scenario, resistance to sliding was zero. Should there be any resistance to sliding, the cause should be ascribed to binding, since no ligation friction was present.

It is also important to note that although the selfligating brackets, ligatures and special brackets are equally effective for classical friction control, they are considerably different in other aspects. One advantage attributed to self-ligating brackets is faster seating and removal of orthodontic archwires as well as longer time intervals in between consultations when compared to conventional elastomeric ligatures. ${ }^{3,10,14,21}$ In addition, self-ligating brackets produce less plaque retention compared to brackets with conventional elastomeric ligatures. ${ }^{15}$ Conversely, the advantages of ligatures and special brackets over self-ligating brackets are lower cost and the attractiveness of colorful elastomeric ligatures, which arouse the interest of children and adolescents.

\section{CONCLUSIONS}

Damon MX, Easy Clip, Smart Clip, Synergy bracket systems as well as the 8-shaped ligature are equally effective alternatives for controlling classical friction with 0.014-in NiTi wire and $0.019 \times 0.025$-in steel wire.

In-Ovation brackets proved effective in reducing classical friction with 0.014-in NiTi wire, whereas for the $0.019 \times 0.025$-in wire it features the same magnitude of classical friction as used conventional elastomeric ligature.

\section{REFERENCES}

1. Baccetti T, Franchi L. Friction produced by types of elastomeric ligatures in treatment mechanics with the preadjusted appliance. Angle Orthod. 2006 Mar;76(2):211-6.

2. Cacciafesta V, Sfondrini MF, Ricciardi A, Scribante A, Klersy C, Auricchio F. Evaluation of friction of stainless steel and esthetic self-ligating brackets in various bracketarchwire combinations. Am J Orthod Dentofacial Orthop. 2003 Oct;124(4):395-402.

3. Damon $\mathrm{DH}$. The Damon low-friction bracket: a biologically compatible straight-wire system. J Clin Orthod. 1998 Nov;32(11):670-80.

4. Demicheli M, Migliorati MV, Balboni C, Biavati AS. Confronto tra differenti sistemi bracket/filo/legatura - Misurazione in vitro dell'attrito su un'intera arcata. Mondo Ortodontico. 2006:4:273-89.

5. Ehsani S, Mandich MA, El-Bialy TH, Flores-Mir C. Frictional resistance in self-ligating orthodontic brackets and conventionally ligated brackets. A systematic review. Angle Orthod. 2009 May;79(3):592-601.

6. Franchi L, Baccetti T. Forces released during alignment with a preadjusted appliance with different types of elastomeric ligatures. Am J Orthod Dentofacial Orthop. 2006 May;129(5):687-90.

7. Gandini P, Orsi L, Bertoncini C, Massironi S, Franchi L. In vitro frictional forces generated by three different ligation methods. Angle Orthod. 2008 Sep;78(5):917-21

8. Griffiths HS, Sherriff M, Ireland AJ. Resistance to sliding with 3 types of elastomeric modules. Am J Orthod Dentofacial Orthop. 2005 Jun;127(6):670-5; quiz 754.

9. Hain M, Dhopatkar A, Rock P. A comparison of different ligation methods on friction. Am J Orthod Dentofacial Orthop. 2006 Nov;130(5):666-70.

10. Harradine NWT, Birnie DJ. The clinical use of Activa self-ligating brackets. Am J Orthod Dentofacial Orthop. 1996 Mar;109(3):319-28.

11. Kang BS, Baek SH, Mah J, Yang WS. Three-dimensional relationship between the critical contact angle and the torque angle. Am J Orthod Dentofacial Orthop. 2003 Jan;123(1):64-73.

12. Kusy RP, Whitley JQ. Influence of archwire and bracket dimensions on sliding mechanics: derivations and determinations of the critical contact angles for binding. Eur J Orthod. 1999 Apr;21(2):199-208.

13. Kusy R. Influence on binding of third-order torque to second-order angulation. Am J Orthod Dentofacial Orthop. 2004 Jun;125(6):726-32.
14. Maijer R, Smith DC. Time savings with self-ligating brackets. J Clin Orthod. 1990 Jan;24(1):29-31.

15. Pellegrini P, Sauerwein R, Finlayson T, McLeod J, Covell DA, Maier T, et al. Plaque retention by self-ligating vs elastomeric orthodontic brackets: Quantitative comparison of oral bacteria and detection with adenosine triphosphate-driven bioluminescence. Am J Orthod Dentofacial Orthop. 2009 Apr;135(4):426.e1-9; discussion 426-7.

16. Petersen A, Rosenstein S, Kim KB, Israel H. Force decay of elastomeric ligatures: influence on unloading force compared to self-ligation. Angle Orthod. 2009 Sep;79(5):934-8

17. Taloumis LJ, Smith TM, Hondrum SO, Lorton L. Force decay and deformation of orthodontic elastomeric ligatures. Am J Orthod Dentofacial Orthop. 1997 Jan;111(1):1-11.

18. Tecco S, Festa F, Caputi S, Traini T, Di lorio D, Attílio M. Friction of conventional and self-ligating brackets using a 10 bracket model. Angle Orthod. 2005 Nov;75(6):1041-5

19. Tecco S, Di lorio, Cordasco G, Verrochi I, Festa F. An in vitro investigation of the influence of self-ligating brackets, low friction ligatures, and archwire on frictional resistance. Eur J Orthod. 2007 Aug;29(4):390-7.

20. Thomas S, Sherriff M, Birnie D. A comparative in vitro study of the frictional characteristics of two types of self-ligating brackets and two types of preadjusted edgewise brackets tied with elastomeric ligatures. Eur J Orthod. 1998 Oct;20(5):589-96

21. Turnbull NR, Birnie DJ. Treatment efficiency of conventional vs self-ligating brackets: effects of archwire size and material. Am J Orthod Dentofacial Orthop. 2007 Mar;131(3):395-9.

22. Woodside DG, Berger JL, Hanson GH. Self-ligation orthodontics with the speed appliance. In: Graber TM, Vanarsdall RL, Vig KWL. Orthodontics: current principles and techniques. 4th ed. St. Louis (MO): Elsevier Mosby; 2005. p. 717-52 